ISSN 2223-7747

www.mdpi.com/journal/plants

Review

\title{
Homeotic Genes and the ABCDE Model for Floral Organ Formation in Wheat
}

\section{Koji Murai}

Department of Bioscience, Fukui Prefectural University, 4-1-1 Matsuoka-kenjojima, Eiheiji-cho, Yoshida-gun, Fukui 910-1195, Japan; E-Mail: murai@fpu.ac.jp; Tel.: +81-776-61-6000 (ext. 3618); Fax: +81-776-61-6015

Received: 19 April 2013; in revised form: 2 June 2013 / Accepted: 18 June 2013 /

Published: 25 June 2013

\begin{abstract}
Floral organ formation has been the subject of intensive study for over 20 years, particularly in the model dicot species Arabidopsis thaliana. These studies have led to the establishment of a general model for the development of floral organs in higher plants, the so-called ABCDE model, in which floral whorl-specific combinations of class A, B, C, D, or E genes specify floral organ identity. In Arabidopsis, class A, B, C, D, E genes encode MADS-box transcription factors except for the class A gene APETALA2. Mutation of these genes induces floral organ homeosis. In this review, I focus on the roles of these homeotic genes in bread wheat (Triticum aestivum), particularly with respect to the ABCDE model. Pistillody, the homeotic transformation of stamens into pistil-like structures, occurs in cytoplasmic substitution (alloplasmic) wheat lines that have the cytoplasm of the related wild species Aegilops crassa. This phenomenon is a valuable tool for analysis of the wheat ABCDE model. Using an alloplasmic line, the wheat ortholog of DROOPING LEAF $(T a D L)$, a member of the $Y A B B Y$ gene family, has been shown to regulate pistil specification. Here, I describe the current understanding of the ABCDE model for floral organ formation in wheat.
\end{abstract}

Keywords: ABCDE model; floral organ; homeotic gene; MADS-box gene; pistillody; wheat

Abbreviations: $A G, A G A M O U S$; AGL, AGAMOUS LIKE; AP, APETALA; CS, Chinese Spring; DL, DROOPING LEAF; FUL, FRUITFULL; LHS, LEAFY HULL STERILE; MFO, MOSAIC FLORAL ORGAN; MFS, MULTI-FLORET SPIKELET; N26, Norin 26; OsIDS, Os INDETERMINATE 
SPIKELET; PAP, PANICLE PHYTOMER; PI, PISTILLATA; SHP, SHATTERPROOF; SEP, SEPALLATA; SNB, SUPERNUMERARY BRACT; SPW, SUPERWOMAN; STK, SEEDSTICK; VRN, VERNARIZATION.

\section{Introduction}

The ABCDE model for flower development proposes that floral organ identity is defined by five classes of homeotic genes, named A, B, C, D and E [1]. According to the floral quartet models of floral organ specification [2], the A- and E-class protein complex develop sepals as the ground-state floral organs in the first floral whorl, the A-, B- and E-class protein complex specify petals in the second whorl, the B-, C- and E-class protein complex specify stamens in the third whorl, and the C- and E-class protein complex specify carpels in the fourth whorl. Cloning of ABCDE homeotic genes in Arabidopsis showed that they encode MADS-box transcription factors except for the class A gene, APETALA2 (AP2) [3]. In Arabidopsis, the class A MADS-box gene is AP1 [4], the class B genes are $A P 3$ and PISTILLATA $(P I)[5,6]$, the class $\mathrm{C}$ gene is AGAMOUS $(A G)$ [7], and the class $\mathrm{D}$ genes are SEEDSTICK (STK), SHATTERPROOF1 (SHP1) and SHP2 [8,9]. The D-class proteins interact in larger complex with the E-class proteins to specify ovule identity. In the Arabidopsis genome, four class E genes have been found, SEPALLATA1 (SEP1), SEP2, SEP3 and SEP4, which show partially redundant functions in identity determination of sepals, petals, stamens and carpels [10,11]. The diversification of MADS-box genes during evolution has contributed to the wide variation of flower forms in angiosperms [12]. Although they are not included in the conventional ABCDE model, the AGAMOUS LIKE 6 ( $A G L 6$ )-clade genes AGL6 and AGL13, may play a role in floral organ formation, probably in ovule formation [13]. AGL6-clade genes comprise a sister clade of SEP genes and may share an E class function with $S E P$ genes.

Grass species, such as rice (Oryza sativa), wheat (Triticum aestivum) and maize (Zea mays), form a unique reproductive inflorescence unit termed a spikelet $[14,15]$. The spikelet is comprised of florets and is encompassed by two small bract leaves (called glumes in wheat). Inflorescence development in wheat involves a series of stages: first, the inflorescence meristem produces a spikelet meristem as an axillary meristem; next, the spikelet meristem produces a floret meristem as an axillary meristem; finally, the floret meristem produces the floral organs (Figures 1 and 2) [16,17]. Development of the inflorescence in maize and rice is more complicated than in wheat because of the presence of additional axillary branch meristems: the tassel branch and spikelet pair meristem in maize, and the panicle branch meristem in rice $[17,18]$. In wheat, the spikelet is composed of florets that join the axis (rachilla) alternately on opposite sides, and is encompassed by two glumes (Figures 1 and 2). Each spikelet usually has six to eight florets, some of which, in apical positions, can be sterile due to hypoplasia. In each floret, the reproductive organs are enveloped by two leaf-like structures, a lemma and a palea. The lemma and palea are considered to have different origins. The lemma is a bract, which is a leaf subtending the axillary meristem of the spikelet axis; the palea is a prophyll, which is the first leaf formed by the axillary meristem [19]. An individual wheat flower contains one pistil, three stamens and two lodicules. The pistil, which is probably composed of three fused carpels, is the female part of the flower and consists of the ovary containing the ovule and two filamentous styles, each terminating with a feathery stigma. The stamen is composed of a filament and an anther containing 
pollen grains. Lodicules are attached to the ovary, and swell during anthesis forcing the lemma and palea apart to facilitate pollination of the stigma from the dehisced anther. There is evidence that the development of lodicules in rice and petals in Arabidopsis are regulated by a similar mechanism [20], suggesting that the lodicule was originally a modified petal. In summary, a palea, lodicules, stamens and a pistil are wheat floral organs developed in the whorl 1, 2, 3, and 4, respectively. Analysis of $\mathrm{ABCDE}$ genes in monocot species such as rice suggests that the ABCDE model might equally apply to monocots [18,21]. Here, we focus on application of the ABCDE model to flower development in wheat.

Figure 1. Wheat inflorescences and floral organs. (a) Developing young spike at the floret differentiation stage. The spikelet primordium (Spp) is indicated. Scale bar $=1 \mathrm{~mm}$; (b) The wheat inflorescence (spike, ear, or head) is composed of spikelets (Sp) attached at the nodes of a zigzag rachis (Rs). Scale bar $=2 \mathrm{~cm}$; (c) A spikelet that has been removed from the rachis. The spikelet consists of multiple (usually six to eight) florets attached at the rachilla (Ra). Two small bract leaves called glumes (Gl) enclose the spikelet. Scale bar $=1 \mathrm{~cm}$; (d) A magnified image of an opened floret. In the floret, the reproductive organs, pistil (Pi) and stamens ( $\mathrm{St}$ ) are enveloped by two leaf-like structures, the lemma (Le) and the palea (Pa). The lemma and palea have been separated to make the reproductive organs visible in the figure. Scale bar $=2 \mathrm{~mm}$; (e) An individual flower containing one pistil ( $\mathrm{Pi})$, three stamens ( $\mathrm{St}$ ) and two lodicules (Lo). The palea (Pa) is also indicated. In this figure, the pistil, stamens, lodicules and palea have been removed from the rachilla. Scale bar $=2 \mathrm{~mm}$; (f) A flower from a plant of the pistillody line. The stamens are transformed into pistil-like structure (Pst) with stigmas. Scale bar $=2 \mathrm{~mm}$.

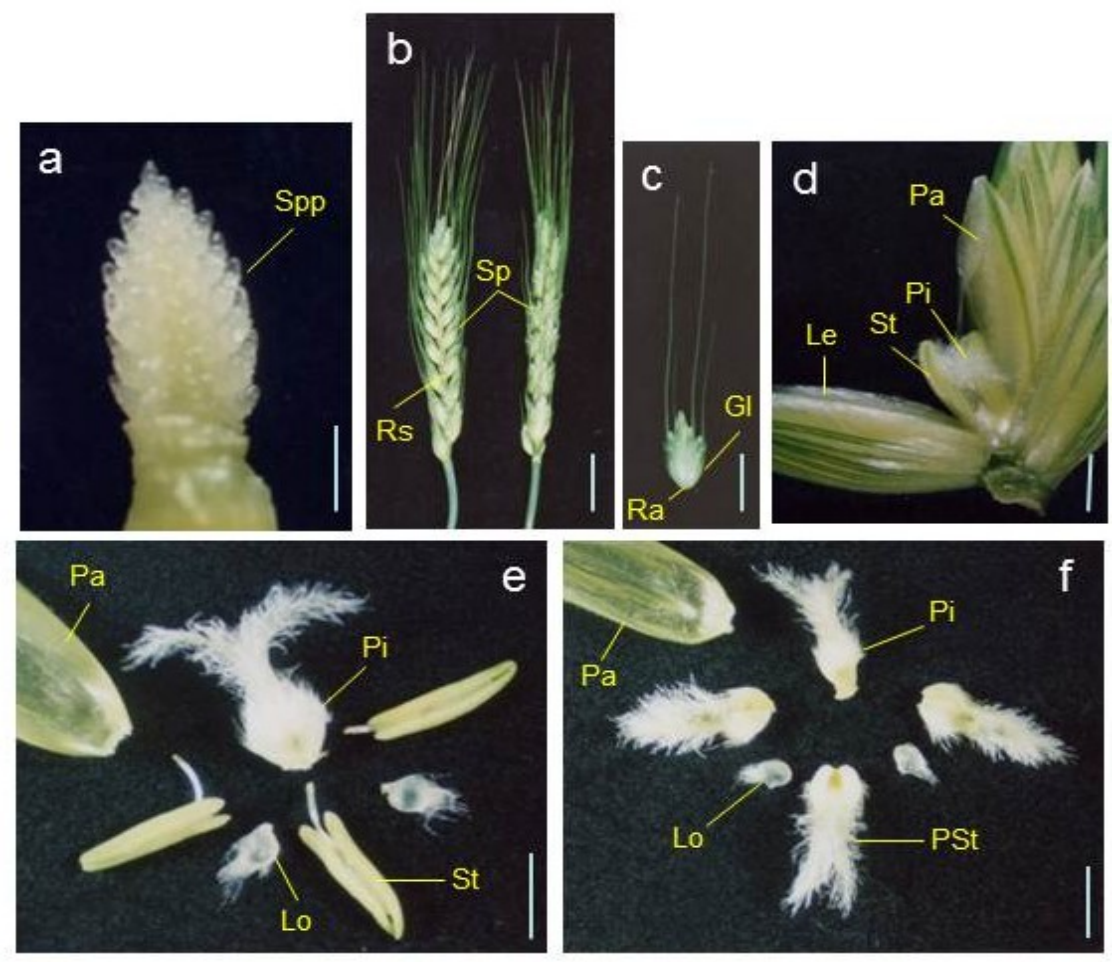


Figure 2. Schematic illustrations of the phytomeric structures of the wheat inflorescence. The spikelets are arranged as two opposite rows of lateral branches from the main axis (rachis). Each spikelet is composed of florets joined at the axis (rachilla) alternately on opposite sides, and enclosed by two glumes. Each floret is composed of a lemma, a palea, two lodicules, three stamens and a pistil. gl, glume; le, lemma; pa, palea; lo, lodicule; st, stamen; pi, pistil.



\section{Summary of ABCDE Model in Rice}

\subsection{Rice Class A Genes}

Three APl-like MADS-box genes have been identified in the rice genome, namely, OsMADS14/RAP1B, OsMADS15/RAP1A and OSMADS18, which are all derived from the FRUITFULL (FUL) lineage rather than $A P 1$ as in Arabidopsis [22]. Studies on transgenic plants suggested that OsMADS14 is involved in promoting flowering and in determining the identity of the floral meristem [23]. Interestingly, analysis of the OSMADS15 mutant degenerative palea (dep) indicated that $O S M A D S 15$ plays a role in palea formation [24]. On the basis that the palea of rice, rather than the lemma, is evolutionarily identical with the sepal of Arabidopsis, then OsMADS15 is likely to be a rice class A gene. However, the dep mutation does not cause defects in the lodicules [24], suggesting that lodicule specification is controlled by another class A gene, an AP2-like gene. It has been reported that overexpression of micro RNA miR172, a negative regulator of $A P 2$, results in the conversion of lodicules into the palea marginal region in transgenic rice plants [25]. Recently, two $A P 2$-like genes, SUPERNUMERARY BRACT (SNB) and Os INDETERMINATE SPIKELET1 (OSIDS1), were identified in rice to be required for lodicule development [26]. $S N B$ and $O S I D S 1$ are positively regulated by another AP2-like gene, MULTI-FLORET SPIKELT1 (MFS1) [27]. Furthermore, these rice AP2-like genes determine inflorescence architecture by regulating changes in spikelet meristem fate. 


\subsection{Rice Class B Genes}

OsMADS2 and OsMADS4 have been reported to be the rice orthologs of $P I$ and to have been generated by an ancient gene duplication event [28]. RNAi suppression of OsMADS2 results in homeotic change to lodicules but stamens still develop normally [29]. By contrast, RNAi suppression of OSMADS4 does not induce any alterations to either lodicules or stamens [30], although simultaneous loss-of-function in both OsMADS2 and OsMADS4 results in conversion of lodicules to palea-like organs and stamens to carpel-like organs [30]. These observations indicate that OsMADS2 plays a more important role than OSMADS4 in lodicule specification, and that OSMADS2 and $O S M A D S 4$ have an equal function in stamen formation.

OsMADS16 /SUPERWOMAN1 (SPW1) is the sole AP3 ortholog in the rice genome [31]. A yeast two-hybrid assay indicated that OsMADS16 interacts with both OsMADS2 and OsMADS4 [32]. Loss-of-function of OSMADS16 causes the same phenotype as RNAi-mediated simultaneous suppression of OSMADS2 and OSMADS4, i.e., the conversion of lodicules and stamens into palea-like and carpel-like organs, respectively [31]. Overall, these findings indicate that the two PI-like genes, $O S M A D S 2$ and OSMADS4, and the AP3-like gene, OSMADS16, are class B genes in rice.

\subsection{Rice Class C Genes}

The duplicated class $\mathrm{C}$ genes in rice, OsMADS3 and OsMADS58, have been reported to show partial conservation of function with the Arabidopsis class $\mathrm{C}$ gene, $A G$. Mutant and transgenic analyses indicated that $O S M A D S 3$ predominantly regulates stamen identity and prevents lodicule development and that $O S M A D S 58$ regulates floral meristem determinacy and normal carpel morphogenesis [33]. However, a recent study on OSMADS3 and OSMADS58 mutants suggested that the two genes redundantly mediate the $C$-function and, together with OSMADS13 (a class D gene), are important for floral meristem determinacy [34]. Furthermore, it is recently reported that the two class $\mathrm{C}$ genes interacts with OSMADS16 (a class B gene) in suppressing indeterminate growth within the floral meristem [35]. Interestingly, carpel identity in rice is determined by a $Y A B B Y$ gene named DROOPING LEAF $(D L)[31,36]$.

\subsection{Rice Class D Genes}

Analyses of expression and of protein-protein interactions suggested that the rice class $\mathrm{D}$ gene OsMADS13 is involved in specifying ovule identity [37,38]. Recent mutation and los-of-function studies of OSMADS13 revealed that it controls ovule specification [39,40]. Mutation of OsMADS21, a paralog of OSMADS13, does not result in any additive ovule defect, indicating that OSMADS21 has lost its ability to determine ovule identity [34,39].

\subsection{Rice Class E Genes}

The class E genes of rice belong to two clades, the SEP-clade and the LOFSEP-clade [41]. In the SEP-clade, OsMADS7/OSMADS45 and OSMADS8/OSMADS24 show high sequence similarity to Arabidopsis SEP genes [41]. Simultaneous suppression of OSMADS7 and OsMADS8 causes severe 
meristic and homeotic effects in the inner three floral whorls; in particular, lodicules are transformed into lemma/palea-like structures [42].

The LOFSEP-clade contains OSMADS1/LEAFY HULL STERILE 1 (LHS1), OSMADS5/OSM5, and OsMADS34/PANICLE PHYTOMER 2 (PAP2) [43]. Mutation of OsMADS1 in rice produces the leafy hull sterile 1 (lhsl) phenotype that has a leaf-like lemma and palea, and lemma/palea-like lodicules [44]. Furthermore, knockdown of OSMADS1 induces the transformation of the lemma into a glume-like structure [45]. These results indicate that OsMADS1 functions in lemma and palea differentiation. In contrast with OSMADS1, mutation of OSMADS34 developed altered inflorescence morphology with altered numbers of primary and secondary branches [46]. These indicate that OSMADS34 and OSMADS1 play important functions in specifying the inflorescence and spikelet. Recently, it was reported that OSMADS34 acts in the shoot apical meristem together with the three AP1/FUL-like genes, OSMADS14, OsMADS15 and OsMADS18, to specify the identity of the inflorescence meristem [47]. Simultaneous silencing of LHS1, OsMADS5, OsMADS7, and OsMADS8 is sufficient to transform all floral organs, except the lemma, into leaf-like structures indicating that the four genes act in concert to provide a class $\mathrm{E}$ function in rice [42].

The rice AGL6-clade gene, OSMADS6/MOSAIC FLORAL ORGANS 1 (MFO1), regulates floral organ identity, suggesting that it also has an E class function [48,49]. Another AGL6-clade gene, OSMADS17, has a minor but redundant function with that of MFO1. Recently, mutant analyses indicated that OsMADS6 plays synergistic roles in floral organ specification with class $\mathrm{B}, \mathrm{C}, \mathrm{D}$ genes and with $D L$ [50]. Furthermore, a null allele of OSMADS6 exhibited transformation of floral organs except for lemma into lemma-like organs [51], indicating that OsMADS6 acts as a critical regulator for floral organ formation.

\section{Pistillody, Homeotic Transformation of Stamens into Pistil-like Structures, in the Alloplasmic Wheat Line}

To investigate the effects of cytoplasm from wild relatives of common wheat (Triticum aestivum) on floral development, cytoplasmic substitution (alloplasmic) lines have been produced by recurrent backcrossing [52,53]. In an alloplasmic line in which Aegilops crassa cytoplasm has been introduced into the wheat cultivar (cv.) Norin 26 (N26), male sterility occurs under long-day conditions ( $>15 \mathrm{~h}$ light period) due to pistillody, the homeotic transformation of stamens into pistil-like structures (Figure 1) [54]. This phenomenon was named photoperiod-sensitive cytoplasmic male sterility (PCMS) and has been extensively investigated to assess its value to hybrid wheat breeding [55]. In contrast to N26, the wheat cv. Chinese Spring (CS) does not show pistillody when Ae. crassa cytoplasm is introduced; the absence of an effect is due to a single dominant gene (designated $R f d 1$ ) located on the long arm of chromosome 7B [56]. The role of $R f d l$ has been investigated by a loss-of-function analysis in an alloplasmic line of CS with ditelosomy of chromosome 7BS, i.e., lacking the long arm of chromosome 7B, and with Ae. crassa cytoplasm $\{$ (cr)-CSdt7BS $\}$. These plants showed pistillody indicating that the absence of $R f d 1$ induces the phenotype irrespective of photoperiod. By contrast, CS plants with ditelosomy of 7BS but with a normal cytoplasm (CSdt7BS) form normal stamens [57]. These results indicate that pistillody is induced by factor(s) in the Ae. crassa cytoplasm, presumably from mitochondrial gene(s), and that the nuclear $R f d 1$ gene prevents 
the deleterious effects of the cytoplasm. PCMS in the alloplasmic lines of N26 suggests the presence of an $R f$ gene that functions under short-day conditions. One candidate for the Ae. crassa cytoplasmic factor causing pistillody in alloplasmic wheat is the mitochondrial gene orf260 [58]. It is also possible that retrograde (mitochondrion to nucleus) signaling via a protein kinase and calmodulin-binding protein may be involved in pistillody induction [59,60]. In the alloplasmic line, an ectopic ovule differentiates in the pistil-like stamens [54,57]. The pistillody line (cr)-CSdt7BS and the corresponding normal line CSdt7BS are useful for investigating the molecular mechanism of the homeotic change of stamens into pistil-like structures with an ectopic ovule induced by a cytoplasmic factor, and for identification of class BCD MADS-box genes. The functions of wheat class BCD MADS-box genes in detail would be examined by the transgenic studies.

\section{Pistillody Reveals the Function of Class BCD MADS-Box Genes in Wheat}

\subsection{Wheat Class B Genes}

In the ABCDE model, the loss-of-function in class $\mathrm{B}$ MADS-box genes $(A P 3$ and $P I$ in Arabidopsis) results in pistillody, the homeotic transformation of stamens into carpel/pistil-like structures. The highly homologous wheat AP3-type genes, TaMADS\#51 and TaMADS\#82, were the first Class B MADS-box genes to be identified [61]. Bread wheat is a hexaploid with the genomic constitution AABBDD in which each genome originated from a different ancestral species. The A genome is believed to derive from T. urartu, the B genome from Aegilops speltoides or another species in the Sitopsis section, and the D genome from Ae. tauschii [62]. Allopolyploidization leads to the generation of duplicated homoeologous genes (homoeologs) and, consequently, the hexaploid wheat genome contains triplicated homoeologs derived from the three ancestral diploid species. TaMADS\#51 and TaMADS\#82 are wheat homoeologs of the AP3 ortholog (wheat APETALA3: WAP3) and are located on chromosomes $7 \mathrm{~B}$ and 7D, respectively. A northern blot analysis showed that expression of $W A P 3$ is restricted to young spikes at the floral organ developing stage, suggesting that WAP3 functions in floral organ formation [61]. The level of expression of WAP3 is reduced in the pistillody line compared to the normal line [57]. WAP3 has also been called TaAP3 [63].

Two PI-type genes have been identified in wheat, namely WPI1 (wheat PISTILLATA1) and WPI2 [64]. A phylogenetic analysis using the deduced amino acid sequences indicated that $W P I 1$ and WPI2 are orthologs of the rice PI-type genes OSMADS4 and OSMADS2, respectively. WPII and WPI2 have also been called TaPI-1 and TaPI-2/TaAGL26, respectively [63,65].

An in situ expression analysis showed that WPI and WAP3 are expressed in the primordia of the stamen and lodicule in the normal wheat line; however, no transcripts were detectable in the pistil-like stamens of the pistillody line [64]. This finding indicates that pistillody results from a deficit of WPI and WAP3 expression in whorl 3, suggesting that these genes have a class B function.

\subsection{Wheat Class C Genes}

The $A G$ orthologs of wheat, WAG1 (wheat AGAMOUS1) and WAG2, were identified as class $\mathrm{C}$ genes [66,67]. The level of transcription of $W A G$ genes is low at the early stages of initiation of floral organ primordia and at its highest at the booting to heading stages. An in situ expression analysis 
indicated that $W A G$ genes are associated with pistil and pistilloid stamen formation in the alloplasmic line [68]. A phylogenetic analysis using the deduced amino acid sequences showed that WAG1 and $W A G 2$ are orthologs of the rice $A G$-type genes, OsMADS58 and OSMADS3, respectively [67,69]. $W A G 1$ and $W A G 2$ are also called TaAG-1 and TaAG-2/TaAGL39, respectively [63,65].

\subsection{Wheat Class D Genes}

Two studies in wheat have identified five genes, TaAGL2, TaAGL9, TaAGL31, TaAG-3A and $T a A G-3 B$ as candidate orthologs of the rice class D gene, OsMADS13 [63,65]. Subsequent sequence analyses showed that TaAG-3A is identical with TaAGL9, and TaAG-3B is identical with TaAGL2. Furthermore, TaAGL2, TaAGL9 and TaAGL31 show very high sequence similarity suggesting that may be homoeologous. These wheat orthologs of Arabidopsis STK have been renamed as WSTK (wheat SEEDSTICK) [68].

In alloplasmic wheat, ectopic expression of the class D gene WSTK occurs in the adaxial region of pistil-like stamens and ectopic ovule primordia are initiated in these regions [68]; this suggests that WSTK expression is involved in ectopic ovule formation in pistil-like stamens. In Arabidopsis, STK functions in ovule development by an interaction with the class C-lineage MADS-box genes, $A G$, SHP1 and SHP2, which is mediated by the class E gene SEP3 [8]. In the pistil-like stamens of alloplasmic wheat, ectopic expression of the class C MADS-box genes, WAG1 and WAG2, and the class D gene WSTK is induced [68]. Furthermore, WSTK protein forms a complex with the class E protein, WSEP, but not with the class C proteins WAG1 and WAG2 [68]. These facts suggest that WSTK has a class D function in wheat, similar to STK in Arabidopsis.

\subsection{Wheat DLOOPING LEAF Gene, TaDL}

In rice, carpel (pistil) specification is regulated by the DROOPING LEAF $(D L)$ gene that encodes a YABBY transcription factor [36]. $T a D L$, a $D L$ ortholog in wheat, was identified by homology screening [70]. In situ expression analysis in the pistillody line showed that $T a D L$ is expressed in the primordia of pistil-like stamens as well as in the pistil. This suggests that $T a D L$ functions in specification of the pistil. Together with the observation that class B genes are not detected in the primordia of pistil-like stamens [64], these facts suggest mutual repression between $T a D L$ and class B genes.

\section{Other Homeotic Genes in Wheat}

\subsection{Wheat Class E Genes}

With regard to SEP-like genes, two MADS-box genes, WSEP (wheat SEPALLATA) and WLHS1 (wheat LEAFY HULL STERILE 1) have been identified in wheat [71]. Phylogenetic analysis showed that WSEP clusters in the same group as OsMADS24 and OsMADS45. In situ hybridization experiments showed that WSEP is expressed in the inner three whorls (lodicules, stamens and pistils) at the floral organ differentiation stage. Interestingly, after floral organ identities have been determined, strong expression of WSEP is observed in the palea, suggesting that WSEP genes are not only involved in floral organ differentiation but also in their subsequent development. The palea-specific expression was also observed in rice OsMADS6 (an AGL6-like gene), suggesting the unique role of class E gene 
in grasses [72]. Yeast two- and three-hybrid analyses indicated that WSEP forms a complex with wheat class B and C genes [71], in a similar fashion to Arabidopsis SEP3 [73].

In addition to WSEP, TaMADS1 has been identified and characterized as a wheat class E gene [74]. A phylogenetic study indicated that WSEP is an ortholog of rice OSMADS45 and that TaMADS1 corresponds to OsMADS24; this suggests that SEP orthologs have diverged into two groups in monocot species [71]. Transgenic Arabidopsis plants over-expressing TaMADS1 show early flowering and terminal flower formation [74]. Although protein-protein interactions involving TaMADS1 and wheat class $\mathrm{B}$ or $\mathrm{C}$ genes have not yet been examined, TaMADS1 may have a similarity as WSEP, because over-expression of WSEP in Arabidopsis causes early flowering and terminal flower formation [71].

Based on phylogenetic studies, WLHS1 is a wheat ortholog of OSMADS1 [71], a member of LOFSEP-clade. Transcripts of WLHS1 accumulate at high levels in the glume, lemma and palea, and at a low level in the pistil and stamen. It has been reported that OsMADS1-like gene expression in inflorescences varies among grasses such as Sorghum bicolor, Chasmanthium latifolium, Avena sativa, and Pennisetum glaucum [75]. The differences in the expression patterns of OSMADS1-like genes in wheat and other grass species may be associated with differences in the structures of their respective inflorescences.

In wheat, five genes, TaMADS\#12, TaAGL37, TaAGL6-1A, TaAGL6-1B and TaAGL-1C, have been identified as candidate orthologs of $A G L 6$-like genes [61,63,65]. TaMADS\#12 and TaAGL6-1B are identical, as are TaAGL37 and TaAGL6-1A; this suggests that these genes are homoeologs. The function of wheat $A G L 6$-like genes has yet to be ascertained.

\subsection{Wheat Class A Genes}

Arabidopsis has two class A genes, $A P 1$ and $A P 2$. The $A P 1$ MADS-box gene functions in the specification of floral meristem identity and in the determination of sepal development. There are two other APl-like genes, FRUITFULL (FUL) and CAULIFLOWER (CAL), which have redundancy of function in specification of floral meristem identity with $A P 1$ [76]. Sequence analysis of $A P 1$-like genes in monocots suggests that they only have FUL-like proteins, in contrast to dicot species, which have AP1, FUL and CAL proteins [22].

The grass family genome has three paralogs of $A P 1 / F U L$-like genes, namely, FUL1 (corresponding to VERNALIZATION1 (VRN1) in wheat), FUL2 and FUL3, which are all derived from the FUL lineage [22]. Wheat FUL1, WFUL1/VRN1, has no class A function but acts in phase transition from vegetative to reproductive growth [77-80]. A phylogenetic analysis using the deduced amino acid sequences showed that WFUL1, WFUL2 and WFUL3 are orthologs of the rice AP1-type genes, OsMADS14, OsMADS15 and OSMADS18, respectively [81].

In young spikes, expression of WFUL2 is greatly reduced in stamens and cannot be detected in pistils, whereas WFUL1/VRN1 and WFUL3 are expressed in all floral organs [81], suggesting that WFUL2 has a different function in the outer floral organs (lemma and palea) compared to the inner floral organs (stamen and pistil). Yeast two- and three-hybrid analyses showed that WFUL2 interacts with class B and class E proteins [81]. In combination with the expression analyses, these observations suggest that WFUL2 specifies the identity of the outer floral organs in the wheat floret. In rice, both 
FUL1 and FUL2 proteins (OsMADS14 and OsMADS15, respectively) interact with a class E protein (OsMADS1/LHS1) [82], suggesting that the diversification of function between FUL1 and FUL2 detected in wheat has not occurred in rice. Especially, it is notable that wheat FUL1 (WFUL1/VRN1) has important role at leaves as well as at shoot apex in flowering [81]. Expression and protein-protein interaction studies suggested that WFUL2 in wheat has a class A function in development of the outer floral organs (lemma and palea) in combination with class B and class E MADS-box genes [81].

The wheat $Q$ gene has been identified as an $A P 2$-like gene [83]. The $q$ allele confers a 'speltoid' spike phenotype that is characterized by a loosely formed head structure with elongated rachis and non-free-threshing seed. A phylogenetic analysis found that $Q$ is not orthologous to Arabidopsis AP2; rather, another $A P 2$-like gene, $T a A P 2$, is the $A P 2$ ortholog [84]. The barley $A P 2$ ortholog, $H v A P 2 / C l y 1$ is associated with lodicule development [85], suggesting that TaAP2 in wheat functions in floral organ formation, especially in lodicule development. Together with the observations in rice AP2-like genes [26,27], these findings may imply that the $A P 2$-like gens in grasses have common function in floral organ formation.

\section{Wheat ABCDE Model, Complicated Homoeologous Gene Interaction}

The wheat ABCDE model for floral organ formation is illustrated in Figure 3. The relationships of homeotic genes among Arabidopsis, rice and wheat are shown in Table 1. As mentioned earlier, wheat is an allohexaploid species with the genome constitution AABBDD. Consequently, the hexaploid wheat genome contains triplicated homoeologs derived from the three ancestral A, B and D genomes. There are three possible evolutionary fates for homoeologs in polyploids: functional diversification, gene silencing, and retention of original or similar function [86]. Functional diversification of homoeologs is one of the important factors in the evolutionary success of polyploid species [87].

With regard to class E genes, analyses of gene structure, expression patterns and protein functions showed no evolutionary changes to the WSEP homoeologs. In contrast, the three WLHS1 homoeologs show genetic and epigenetic alterations [71]. The A genome WLHS1 homoeolog (WLHS1-A) has a large deletion in the region of the $\mathrm{K}$ domain sequence. Data from a yeast two-hybrid analysis and a transgenic experiment indicated that the WLHS1-A protein does not have a function in floral development. WLHS1-B and WLHS1-D, located in the B and D genomes, respectively, have the complete MADS-box gene structure; however, $W L H S 1-B$ is effectively silenced by epigenetic regulation. Consequently, of the three homoeologs, only WLHS1-D functions in hexaploid wheat.

The example of the WLHS1 genes indicates the possibility that homoeologs of each homeotic gene may be differentially regulated in wheat spike formation. Floral homeotic MADS domain proteins interact in floral tissue as proposed in the "floral quartet" model, in which a tetramer of MADS domain proteins functions in specification of floral organ identity [2,73]. The complex homoeologous gene interactions are probably associated with morphological, physiological and ecological diversification among different ploidy levels. Polyploid wheat must be a good model for investigating this point [88]. 
Figure 3. The ABCDE model of floral organ formation in wheat. In contrast to the Arabidopsis ABCDE model, the wheat ABCDE model involves duplicated genes for class $\mathrm{B}$ (PI-like) and class $\mathrm{C}$ ( $A G$-like) functions. Furthermore, class $\mathrm{E}$ genes are divided into two groups, WSEP and WLHS1, with sub-functionalization. A $Y A B B Y$ gene TaDL specifies the pistil (carpel) identity. The pistillody line has been valuable for constructing the ABCDE model in wheat. The wheat ABCDE model is similar to that of rice except for the class A genes. The current wheat ABCDE model indicates that class $\mathrm{B}$ and TaDL proteins show mutual suppression, which was suggested from analysis of a pistillody line. The mutual suppression between class $\mathrm{A}$ and $\mathrm{C}$ genes is also postulated here. The wheat ABCDE model probably functions through complex homoeologous gene interactions.

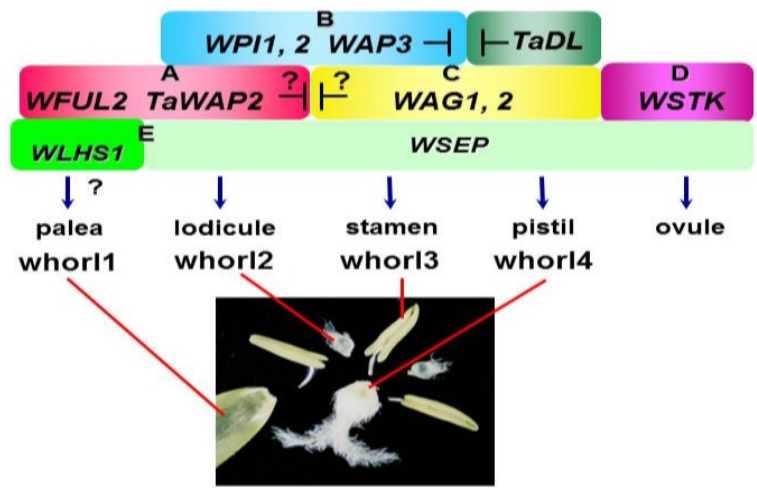

Table 1. The relationships of homeotic genes among Arabidopsis, rice and wheat.

\begin{tabular}{|c|c|c|c|c|}
\hline Class & Clade & Arabidopsis & Rice & Wheat \\
\hline \multirow[t]{6}{*}{ class A } & & $A P 1$ & OsMADS14/RAPIB & WFUL1/VRN1 \\
\hline & & & OsMADS15/RAP1A & WFUL2 \\
\hline & & & OsMADS18 & WFUL3 \\
\hline & & $A P 2$ & $S N B$ & TaAP2 \\
\hline & & & OsIDS1 & $Q$ \\
\hline & & & MFS1 & \\
\hline \multirow[t]{3}{*}{ class B } & & $A P 3$ & OsMADS16/SPW1 & WAP3/TaAP3 * \\
\hline & & $P I$ & OsMADS2 & WPI2/TaPI-2/TaAGL26 \\
\hline & & & OsMADS4 & WPII/TaPI-1 \\
\hline \multirow[t]{2}{*}{ class $\mathrm{C}$} & & $A G$ & OsMADS3 & WAG2/TaAG-2/TaAGL39 \\
\hline & & & OsMADS58 & WAG1/TaAG-1 \\
\hline class D & & $\begin{array}{c}\text { STK } \\
\text { SHP1, } 2\end{array}$ & OsMADS13 & WSTK $* *$ \\
\hline \multirow[t]{6}{*}{ class E } & SEP & $S E P 1,2,3,4$ & OsMADS7/OsMADS45 & WSEP \\
\hline & & & OsMADS8/OsMADS24 & TaMADS1 \\
\hline & LOFSEP & & OsMADS1/LHS1 & WLHSI \\
\hline & & & OsMADS5/OSM5 & \\
\hline & & & OsMADS34/PAP2 & \\
\hline & AGL6 & $(A G L O)$ & $\begin{array}{c}\text { OsMADS6/MFO1 } \\
\text { OsMADS17 }\end{array}$ & TaAGL6 *** \\
\hline \multicolumn{2}{|l|}{ other } & $(C R C)$ & $D L$ & $T a D L$ \\
\hline \multicolumn{5}{|c|}{$\begin{array}{l}\text { TaMADS\#51 and TaMADS\#82 are two of three homoeologs of WAP3; ** TaAGL2/TaAG-3B } \\
a A G L 9 / T a A G-3 A \text { and TaAGL31 are homoeologs of WSTK; *** TaAGL6-1A/TaAGL37, TaAGL6 } \\
\text { B/TaMADS\#12 and TaAGL6-1C are homoeologs of TaAGL6. }\end{array}$} \\
\hline
\end{tabular}




\section{Acknowledgments}

This work was supported by the Grant-in-Aid for Scientific Research on Innovative Areas (The Ministry of Education, Culture, Sports, Science and Technology (MEXT) KAKENHI Grant Number 24113517).

\section{Conflict of Interest}

There is no conflict of interest.

\section{References}

1. Rijpkema, A.S.; Vandenbussche, M.; Koes, R.; Heijmans, K.; Gerats, T. Variations on a theme: Changes in the floral ABCs in angiosperms. Semin. Cell Dev. Biol. 2010, 21, 100-107.

2. Smaczniak, C.; Immink, R.G.H.; Angenent, G.C.; Kaufmann, K. Developmental and evolutionary diversity of plant MADS-domain factors: Insights from recent studies. Development 2012, 139, 3081-3098.

3. Jofuku, K.D.; den Boer, B.G.; Montagu, M.V.; Okamuro, J.K. Control of Arabidopsis flower and seed development by the homeotic gene APETALA2. Plant Cell 1994, 6, 1211-1225.

4. Mandel, M.A.; Gustafson-Brown, C.; Savidge, B.; Yanofsky, M.F. Molecular characterization of the Arabidopsis floral homeotic gene APETALA1. Nature 1992, 360, $273-277$.

5. Jack, T.; Brockman, L.L.; Meyerowitz, E.M. The homeotic gene APETALA3 of Arabidopsis thaliana encodes a MADS box and is expressed in petals and stamens. Cell 1992, 68, 683-697.

6. Goto, K.; Meyerowitz, E.M. Function and regulation of the Arabidopsis floral homeotic gene PISTILLATA. Genes Dev. 1994, 8, 1548-1560.

7. Yanofsky, M.F.; Ma, H.; Bowman, J.L.; Drews, G.N.; Feldmann, K.A.; Meyerowitz, E.M. The protein encoded by the Arabidopsis homeotic gene agamous resembles transcription factors. Nature 1990, 346, 35-39.

8. Favaro, R.; Pinyopich, A.; Battaglia, R.; Kooiker, M.; Borghi, L.; Ditta, G.; Yanofsky, M.F.; Kater, M.M.; Colombo, L. MADS-box protein complexes control carpel and ovule development in Arabidopsis. Plant Cell 2003, 15, 2603-2611.

9. Pinyopich, A.; Ditta, G.S.; Savidge, B.; Liljegren, S.J.; Baumann, E.; Wisman, E.; Yanofsky, M.F. Assessing the redundancy of MADS-box genes during carpel and ovule development. Nature 2003, 424, 85-88.

10. Pelaz, S.; Ditta, G.S.; Baumann, E.; Wisman, E.; Yanofsky, M.F. B and C floral organ identity functions require SEPSLLATA MADS-box genes. Nature 2000, 405, 200-203.

11. Ditta, G.; Pinyopich, A.; Robles, P.; Pelaz, S.; Yanofsky, M.F. The SEP4 gene of Arabidopsis thaliana functions in floral organ and meristem identity. Curr. Biol. 2004, 14, 1935-1940.

12. Litt, A.; Kramer, E.M. The ABC model and the diversification of floral organ identity. Semin. Cell Dev. Biol. 2010, 21, 129-137.

13. Schauer, S.E.; Schluter, P.M.; Baskar, R.; Gheyselinck, J.; Bolanos, A.; Curtis, M.D.; Grossniklaus, U. Intronic regulatory elements determine the divergent expression patterns of AGAMOUS-LIKE6 subfamily members in Arabidopsis. Plant J. 2009, 59, 987-1000. 
14. Schmidt, R.J.; Ambrose, B.A. The blooming of grass flower development. Curr. Opin. Plant Biol. 1998, 1, 60-67.

15. Bommert, P.; Satoh-Nagasawa, N.; Jackson, D.; Hirano, H.-Y. Genetics and evolution of inflorescence and flower development in grasses. Plant Cell Physiol. 2005, 46, 69-78.

16. Murai, K.; Takumi, S.; Koga, H.; Ogihara, Y. Pistillody, homeotic transformation of stamens into pistil-like structures, caused by nuclear-cytoplasm interaction in wheat. Plant J. 2002, 29, 169-181.

17. Shitsukawa, N.; Takagishi, A.; Ikari, C.; Takumi, S.; Murai, K. WFL, a wheat FLORICAULA/LEAFY ortholog, is associated with spikelet formation as lateral branch of the inflorescence meristem. Genes Genet. Syst. 2006, 81, 13-20.

18. Ciaffi, M.; Paolacci, A.R.; Tanzarella, O.A.; Porceddu, E. Molecular aspects of flower development in grasses. Sex. Plant Reprod. 2011, 24, 247-282.

19. Kellogg, E.A. Evolutionary history of the grasses. Plant Physiol. 2001, 125, 1198-1205.

20. Yoshida, H. Is the lodicule a petal: Molecular evidence? Plant Sci. 2012, 184, 121-128.

21. Yoshida, H.; Nagato, Y. Flower development in rice. J. Exp. Bot. 2011, 62, 4719-4730.

22. Litt, A.; Irish, V.F. Duplication and diversification in the APETALA1/FRUITFULL floral homeotic gene lineage: Implications for the evolution of floral development. Genetics 2003, 165, $821-833$.

23. Jeon, J.-S.; Lee, S.; Jung, K.-H.; Yang, W.-S.; Yi, G.-H.; Oh, B.-G.; An, G. Production of transgenic rice plants showing reduced heading date and plant height by ectopic expression of rice MADS-box genes. Mol. Breed. 2000, 6, 581-592.

24. Wang, K.; Tang, D.; Hong, L.; Xu, W.; Huang, J.; Li, M.; Gu, M.; Xue, Y.; Cheng, Z. DEP and $A F O$ regulate reproductive habit in rice. PLoS Genet. 2010, 6, e1000818.

25. Zhu, Q.-H.; Upadhyaya, N.M.; Gubler, F.; Helliwell, C.A. Over-expression of miR172 causes loss of spikelet determinacy and floral organ abnormalities in rice (Oryza sativa). BMC Plant Biol. 2009, 9, 149.

26. Lee, D.-Y.; An, G. Two AP2 family genes, SUPERNUMERARY BRACT (SNB) and OSINDETERMINATE SPIKELET 1 (OSIDS1), synergistically control inflorescence architecture and floral meristem establishment in rice. Plant J. 2012, 69, 445-461.

27. Ren, D.; Li, Y.; Zhao, F.; Sang, X.; Shi, J.; Wang, N.; Guo, S.; Ling, Y.; Zhang, C.; Yang, Z.; et al. MULTI-FLORET SPIKELET1, which encodes and AP2/ERF protein, determines spikelet meristem gate and sterile lemma identity in rice. Plant Physiol. 2013, doi:10.1104/pp.113.216044.

28. Chung, Y.-Y.; Kim, S.-R.; Kang, H.-G.; Noh, Y.-S.; Park, M.C.; Finkel, D.; An, G. Characterization of two rice MADS box genes homologous to GLOBOSA. Plant Sci. 1995, 109, $45-56$.

29. Prasad, K.; Vijayraghavan, U. Double-stranded RNA interference of a rice PI/GLO paralog, OsMADS2, uncovers its second-whorl-specific function in floral organ patterning. Genetics 2003, 165, 2301-2305.

30. Yao, S.-G.; Ohmori, S.; Kimizu, M.; Yoshida, H. Unequal genetic redundancy of rice PISTILLATA orthologs, OsMADS2 and OsMADS4, in lodicule and stamen development. Plant Cell Physiol. 2008, 49, 853-857. 
31. Nagasawa, N.; Miyoshi, M.; Sano, Y.; Satoh, H.; Hirano, H.-Y.; Sakai, H.; Nagato, Y. SUPERWOMAN1 and DROOPING LEAF genes control floral organ identity in rice. Development 2003, 130, 705-718.

32. Yoshida, H.; Itoh, J.-I.; Ohmori, S.; Miyoshi, K.; Horigome, A.; Uchida, E.; Kimizu, M.; Matsumura, Y.; Kusaba, M.; Satoh, H.; et al. Superwoman1-cleistogamy, a hopeful allele for gene containment in GM rice. Plant Biotechnol. J. 2007, 5, 835-846.

33. Yamaguchi, T.; Lee, D.Y.; Miyao, A.; Hirochika, H.; An, G.; Hirano, H.-Y. Functional diversification of the two C-class MADS box genes OSMADS3 and OSMADS58 in Oryza sativa. Plant Cell 2006, 18, 15-28.

34. Dreni, L.; Pilatone, A.; Yun, D.; Erreni, S.; Pajoro, A.; Caporali, E.; Zhang, D.; Kater, M.M. Functional analysis of all AGAMOUS subfamily members in rice reveals their roles in reproductive organ identity determination and meristem determinacy. Plant Cell 2011, 23, 2850-2863.

35. Yun, D.; Liang, W.; Dreni, L.; Yin, C.; Zhou, Z.; Kater, M.M.; Zhang, D. OsMADS16 interacts with OsMADS3 and OsMADS58 in specifying floral patterning in rice. Mol. Plant 2013, doi: $10.1093 / \mathrm{mp} / \mathrm{sst} 003$.

36. Yamaguchi, T.; Nagasawa, N.; Kawasaki, S.; Matsuoka, M.; Nagato, Y.; Hirano, H.-Y. The YABBY gene DROOPING LEAF regulates carpel specification and midrib development in Oryza sativa. Plant Cell 2004, 16, 500-509.

37. Lopez-Dee, Z.P.; Wittich, P.; Pé, M.E.; Rigora, D.; del Buono, I.; Sari Gorla, M.; Kater, M.M.; Colombo, L. OSMADS13, a novel rice MADS-box gene expressed during ovule development. Dev. Genet. 1999, 25, 237-244.

38. Favaro, R.; Immink, R.G.H.; Ferioli, V.; Bernasconi, B.; Byzova, M.; Angenent, G.C.; Kater, M.M.; Colombo, L. Ovule-specific MADS-box proteins have conserved protein-protein interactions in monocot and dicot plants. Mol. Genet. Genomics 2002, 268, 152-159.

39. Dreni, L.; Jacchia, S.; Fornara, F.; Fornari, M.; Ouwerkerk, P.B.E.; An, G.; Colombo, L.; Kater, M.M. The D-lineage MADS-box gene OsMADS13 controls ovule identity in rice. Plant J. 2007, 52, 690-699.

40. Yamaki, S.; Nagato, Y.; Kurata, N.; Nonomura, K. Ovule is a lateral organ finally differentiated from the terminating floral meristem in rice. Dev. Biol. 2011, 351, 208-216.

41. Malcomber, S.T.; Kellogg, E.A. SEPALLATA gene diversification: Brave new whorls. Trends Plant Sci. 2005, 10, 427-435.

42. Cui, R.; Han, J.; Zhao, S.; Su, K.; Wu, F.; Du, X.; Xu, Q.; Chong, K.; Theissen, G.; Meng, Z. Functional conservation and diversification of class $\mathrm{E}$ floral homeotic genes in rice (Oryza sativa). Plant J. 2010, 61, 767-781.

43. Christensen, A.R.; Malcomber, S.T. Duplication and diversification of the LEAFY HULL STERILE1 and Oryza sativa MADS5 SEPALLATA lineages in graminoid Poales. EvoDevo 2012, 3,4 .

44. Jeon, J.-S.; Jang, S.; Lee, S.; Nam, J.; Kim, C.; Lee, S.-H.; Chung, Y.-Y.; Kim, S.-R.; Lee, Y.H.; Cho, Y.-G.; et al. Leafy hull sterilel is a homeotic mutation in a rice MADS box gene affecting rice flower development. Plant Cell 2000, 12, 871-884. 
45. Prasad, K.; Parameswaran, S.; Vijayraghavan, U. OsMADS1, a rice MADS-box factor, controls differentiation of specific cell types in the lemma and palea and is an early-acting regulator of inner floral organs. Plant J. 2005, 43, 915-928.

46. Gao, X.; Liang, W.; Yin, C.; Ji, S.; Wang, H.; Su, X.; Guo, C.; Kong, H.; Xue, H.; Zhang, D. The SEPALLATA-like gene OSMADS34 is required for rice inflorescence and spikelet development. Plant Physiol. 2010, 153, 728-740.

47. Kobayashi, K.; Yasuno, N.; Sato, Y.; Yoda, M.; Yamazaki, R.; Kimizu, M.; Yoshida, H.; Nagamura, Y.; Kyozuka, J. Inflorescence meristem identity in rice is specified by overlapping functions of three AP1/FUL-like MADS box genes and PAP2, a SEPALLATA MADS box gene. Plant Cell 2012, 24, 1848-1859.

48. Ohmori, S.; Kimizu, M.; Sugita, M.; Miyao, A.; Hirochika, H.; Uchida, E.; Nagato, Y.; Yoshida, H. MOSAIC FLORAL ORGANS1, an AGL6-like MADS box gene, regulates floral organ identity and meristem fate in rice. Plant Cell 2009, 21, 3008-3025.

49. Li, H.; Liang, W.; Jia, R.; Yin, C.; Zong, J.; Kong, H.; Zhang, D. The AGL6-like gene OsMADS6 regulates floral organ and meristem identities in rice. Cell Res. 2010, 20, 299-313.

50. Li, H.; Liang, W.; Hu, Y.; Zhu, L.; Yin, C.; Xu, J.; Dreni, L.; Kater, M.M.; Zhang, D. Rice MADS6 interacts with the floral homeotic genes SUPERWOMAN1, MADS3, MADS58, MADS13, and DROOPING LEAF in specifying floral organ identities and meristem fate. Plant Cell 2011, 23, 2536-2552.

51. Duan, Y.; Xing, Z.; Diao, Z.; Xu, W.; Li, S.; Du, X.; Wu, G.; Wang, C.; Lan, T.; Meng, Z.; et al. Characterization of Osmads6-5, a null allele, reveals that OsMADS6 is acritical regulator for early flower development in rice (Oryza sativa L.). Plant Mol. Biol. 2012, 80, 429-442.

52. Tsunewaki, K.; Wang, G.-Z.; Matsuoka, Y. Plasmon analysis of Triticum (wheat) and Aegilops. 1. Production of alloplasmic common wheats and their fertilities. Genes Genet. Syst. 1996, 71, 293-311.

53. Tsunewaki, K.; Wang, G.-Z.; Matsuoka, Y. Plasmon analysis of Triticum (wheat) and Aegilops. 2. Characterization and classification of 47 plasmons based on their effects on common wheat phenotype. Genes Genet. Syst. 2002, 77, 409-427.

54. Murai, K.; Tsunewaki, K. Photoperiod-sensitive cytoplasmic male sterility in wheat with Aegilops crassa cytoplasm. Euphytica 1993, 67, 41-48.

55. Murai, K. Genetic effects of an alien cytoplasm on male and female fertility in wheat. Recent Res. Dev. Genet. 2001, 1, 47-54.

56. Murai, K.; Tsunewaki, K. Genetic analysis on the fertility restration by Triticum aestivum cv. Chinese Spring against photoperiod-sensitive cytoplasmic male sterility. Jpn. J. Genet. Genes Genet. Syst. 1994, 69, 195-202.

57. Murai, K.; Takumi, S.; Koga, H.; Ogihara, Y. Pistillody, homeotic transformation of stamens into pistil-like structures, caused by nuclear-cytoplasm interaction in wheat. Plant J. 2002, 29, 169-182.

58. Zhu, Y.; Saraike, T.; Yamamoto, Y.; Hagita, H.; Takumi, S.; Murai, K. orf $260^{\text {cra }}$, a novel mitochondrial gene, is associated with the homeotic transformation of stamen into pistil-like structures (pistillody) in alloplasmic wheat. Plant Cell Physiol. 2008, 49, 1723-1733. 
59. Saraike, T.; Shitsukawa, N.; Yamamoto, Y.; Hagita, H.; Iwasaki, Y.; Takumi, S.; Murai, K. Identification of a protein kinase gene associated with pistillody, homeotic transformation of stamens into pistil-like structures, in alloplasmic wheat. Planta 2007, 227, 211-221.

60. Yamamoto, M.; Shitsukawa, N.; Yamada, M.; Kato, K.; Takumi, S.; Kawaura, K.; Ogihara, Y.; Murai, K. Identification of a novel homolog for a calmodulin-binding protein that is upregulated in alloplasmic wheat showing pistillody. Planta 2013, 237, 1001-1013.

61. Murai, K.; Murai, R.; Takumi, S.; Ogihara, Y. Cloning and Characterization of cDNAs Corresponding to the Wheat MADS Box Genes. In Proceedings of 9th International Wheat Genetics Symposium, Saskatchewan, Canada, 2-7 August 1998; Volume 1, pp. 89-94.

62. Feldman, M. The Origin of Cultivated Wheat. In The World Wheat Book; Bonjean, A.P., Angus, W.J., Eds.; Lavoisier Publisher: Paris, France, 2001; pp. 1-56.

63. Paolacci, A.R.; Tanzarella, O.A.; Porceddu, E.; Varotto, S.; Ciaffi, M. Molecular and phylogenetic analysis of MADS-box genes of MIKC type and chromosome location of SEP-like gene in wheat (Triticum aestivum L.). Mol. Genet. Genomics 2007, 278, 689-708.

64. Hama, E.; Takumi, S.; Ogihara, Y.; Murai, K. Pistillody is caused by alterations to the class-B MADS-box gene expression pattern in alloplasmic wheats. Planta 2004, 218, 712-720.

65. Zhao, T.; Ni, Z.; Dai, Y.; Yao, Y.; Nie, X.; Sun, Q. Characterization and expression of 42 MADS-box genes in wheat (Triticum aestivum L.). Mol. Genet. Genomics 2006, 276, 334-350.

66. Meguro, A.; Takumi, S.; Ogihara, Y.; Murai, K. WAG, a wheat AGAMOUS homolog, is associated with development of pistil-like stamens in alloplasmic wheats. Sex. Plant Reprod. 2003, 15, 221-230.

67. Hirabayashi, C.; Murai, K. Class C MADS-box gene AGAMOUS was duplicated in the wheat genome. Wheat Inf. Serv. 2009, 107, 13-16.

68. Yamada, K.; Saraike, T.; Shitsukawa, N.; Hirabayashi, C.; Takumi, S.; Murai, K. Class D and $\mathrm{B}_{\text {sister }}$ MADS-box genes are associated with ectopic ovule formation in the pistil-like stamens of alloplasmic wheat (Triticum aestivum L.). Plant Mol. Biol. 2009, 71, 1-14.

69. Wei, S.; Peng, Z.; Zhou, Y.; Yang, Z.; Wu, K.; Ouyang, Z. Nucloetide diversity and molecular evolution of the WAG-2 gene in common wheat (Triticum aestivum L.) and its relatives. Genet. Mol. Biol. 2011, 34, 606-615.

70. Ishikawa, M.; Ohmori, Y.; Tanaka, W.; Hirabayashi, C.; Murai, K.; Ogihara, Y.; Yamaguchi, T.; Hirano, H.-Y. The spatial expression patterns of DROOPING LEAF orthologs suggest a conserved function in grasses. Genes Genet. Syst. 2009, 84, 137-146.

71. Shitsukawa, N.; Tahira, C.; Kassai, K.-I.; Hirabayashi, C.; Shimizu, T.; Takumi, S.; Mochida, K.; Kawaura, K.; Ogihara, Y.; Murai, K. Genetic and epigenetic alteration among three homoeologous genes of a class E MADS box gene in hexaploid wheat. Plant Cell 2007, 19, 1723-1737.

72. Reinheimer, R.; Kellogg, E.A. Evolution of AGL6-like MADS box genes in grasses (Poaceae): Ovule expression is ancient and palea expression is new. Plant Cell 2009, 21, 2591-2605.

73. Smaczniak, C.; Immink, R.G.H.; Muino, J.M.; Blanvillain, R.; Busscher, M.; Busscher-Lange, J.; Dinh, Q.D.P.; Liu, S.; Westphal, A.H.; Boeren, S.; et al. Characterization of MADS-domain transcription factor complexes in Arabidopsis flower development. Proc. Natl. Acad. Sci. USA 2012, 109, 1560-1565. 
74. Zhao, X.Y.; Cheng, Z.J.; Zhang, X.S. Overexpression of TaMADS1, a SEPALLATA-like gene in wheat, causes early flowering and the abnormal development of floral organs in Arabidopsis. Planta 2006, 223, 698-707.

75. Malcomber, S.T.; Kellogg, E.A. Heterogeneous expression patterns and separate roles of the SEPALLATA gene LEAFY HULL STERILE1 in grasses. Plant Cell 2004, 16, 1692-1706.

76. Ferrandiz, C.; Gu, Q.; Martienssen, R.; Yanofsky, M.F. Redundant regulation of meristem identity and plant architecture by FRUITFULL, APETALA1 and CAULIFLOWER. Development 2000, 127, 725-734.

77. Yan, L.; Loukoianov, A.; Tranquilli, G.; Helguera, M.; Fahima, T.; Dubcovsky, J. Positional cloning of the wheat vernalization gene VRN1. Proc. Natl. Acad. Sci. USA 2003, 100, 6263-6268.

78. Murai, K.; Miyamae, M.; Kato, H.; Takumi, S.; Ogihara, Y. WAP1, a wheat APETALA1 homolog, plays a central role in the phase transition from vegetative to reproductive growth. Plant Cell Physiol. 2003, 44, 1255-1265.

79. Trevaskis, B.; Bagnall, D.J.; Ellis, M.H.; Peacock, W.J.; Dennis, E.S. MADS box genes control vernalization-induced flowering in cereals. Proc. Natl. Acad. Sci. USA 2003, 100, 13099-13104.

80. Danyluk, J.; Kane, N.A.; Breton, G.; Limin, A.E.; Fowler, D.B.; Sarhan, F. TaVRT-1, a putative transcription factor associated with vegetative to reproductive transition in cereals. Plant Physiol. 2003, 132, 1849-1860.

81. Kinjo, H.; Shitsukawa, N.; Takumi, S.; Murai, K. Diversification of three APETALA1/FRUITFULLlike genes in wheat. Mol. Genet. Genomics 2012, 287, 283-294.

82. Lim, J.; Moon, Y.-H.; An, G.; Jang, S.K. Two rice MADS domain proteins interact with OsMADS1. Plant Mol. Biol. 2000, 44, 513-527.

83. Zhang, Z.; Belcram, H.; Gornicki, P.; Charles, M.; Just, J.; Huneau, C.; Magdelenat, G.; Couloux, A.; Samain, S.; Gill, B.S.; et al. Duplication and partitioning in evolution and function of homoeologous $Q$ loci governing domestication characters in polyploidy wheat. Proc. Natl. Acad. Sci. USA 2011, 108, 18737-18742.

84. Ning, S.; Wang, N.; Sakuma, S.; Pourkheirandish, M.; Wu, J.; Matsumoto, T.; Koba, T.; Komatsuda, T. Structure, transcription and post-transcriptional regulation of the bread wheat orthologs of the barley cleistogamy gene Cly1. Theor. Appl. Genet. 2013, doi:10.1007/s00122-013-2052-6.

85. Nair, S.K.; Wang, N.; Turuspekov, Y.; Pourkheirandish, M.; Sinsuwongwat, S.; Chen, G.; Sameri, M.; Tagiri, A.; Honda, I.; Watanabe, Y.; et al. Cleistogamous flowering in barley arises from the suppression of microRNA-guided HvAP2 mRNA cleavage. Proc. Natl. Acad. Sci. USA 2010, 107, 490-495.

86. Wendel, J.F. Genome evolution in polyploids. Plant Mol. Biol. 2000, 42, 225-249.

87. Te Beest, M.; Le Roux, J.J.; Richardson, D.M.; Brysting, A.K.; Suda, J.; Kubesova, M.; Pysek, P. The more the better? The role of polyploidy in facilitating plant invasions. Ann. Bot. 2012, 109, 19-45.

88. Shitsukawa, N.; Kinjo, H.; Takumi, S.; Murai, K. Heterochronic development of the floret meristem determines grain number per spikelet in diploid, tetraploid and hexaploid wheats. Ann. Bot. 2009, 104, 243-251.

(C) 2013 by the authors; licensee MDPI, Basel, Switzerland. This article is an open access article distributed under the terms and conditions of the Creative Commons Attribution license (http://creativecommons.org/licenses/by/3.0/). 